\title{
Functional design of wave protection structures and layout for a special situated marina
}

Frank Weichbrodt, Christian Schlamkow, Torsten Haverland

\section{Problem and Objective}

Between the breakwaters of the harbour entrance of Rostock-Warnemünde, located at the Baltic Coast of Germany, a small marina is situated. In 1999 these breakwaters were modified in order to meet the nautical requirements of larger ships.

From this time on, serious problems for the pleasure boats were observed due to wave disturbance. New structural measures like floating breakwaters and vertical walls (small length) showed only poor improvements.

The objective of the investigations was the functional design of wave protection structures and a layout able to meet the user requirements on a modern marina with focus on competitive sailing sports. The investigations were assigned by the Sport Confederation of the Federal State of Mecklenburg-Vorpommern, Germany.

To accomplish this objective, numerical simulations as well as small scale hydraulic tests were performed at the University of Rostock.

\section{Investigations}

- site review and determination of user requirements

- determination of the sea state with the numerical model SWAN to generate input data (wave height, period and direction)

- prediction of wave propagation for the harbour entrance and the marina using the numerical model MIKE 21 EMS

- refraction, diffraction, reflection and transmission effects for 16 alternative wave protection structure configurations with different reflection properties

- alternatives with good results (criteria wave height) were additionally tested in a small scale hydraulic model (4x4 m wave tank at the University of Rostock)

- development of different berth layouts in order to optimize the number of berths and to offer a variety of possibilities for the usage of the harbour

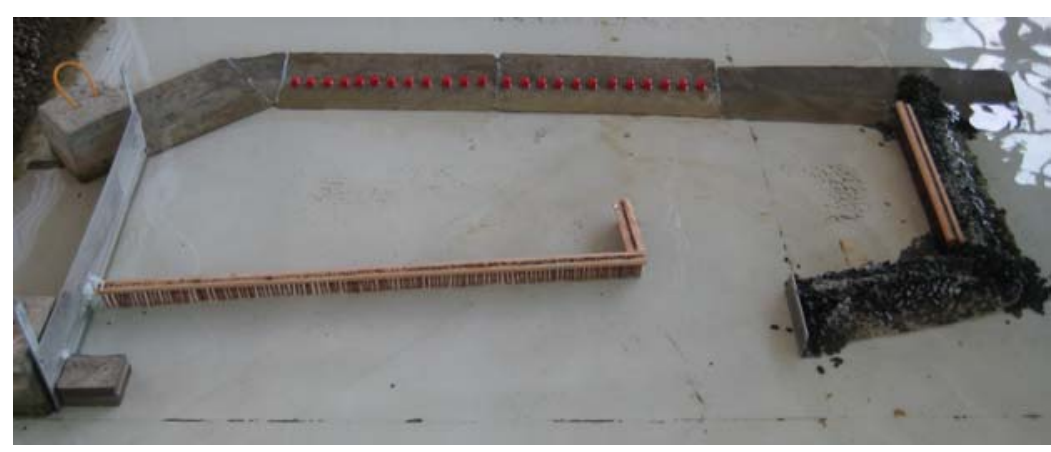

(n)
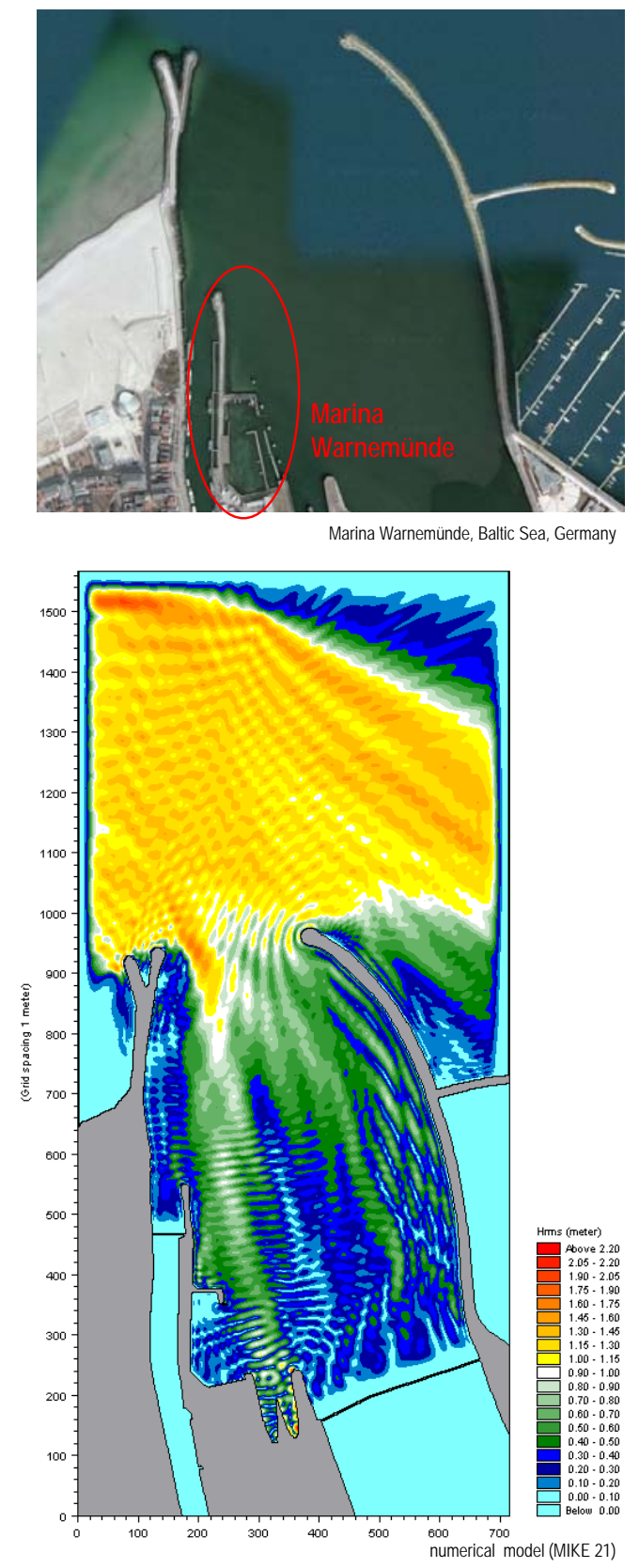

Results

- sea state at the berths inside of the marina for all of the $\mathbf{1 6}$ alternatives

- recommendations for the functional design of wave protection structures

- recommendations for the berth layout of the planned marina which meets the user and operator

requirements on a modern marina

- optimisation of slipways and other harbour facilities

- construction works will start in autum 2010
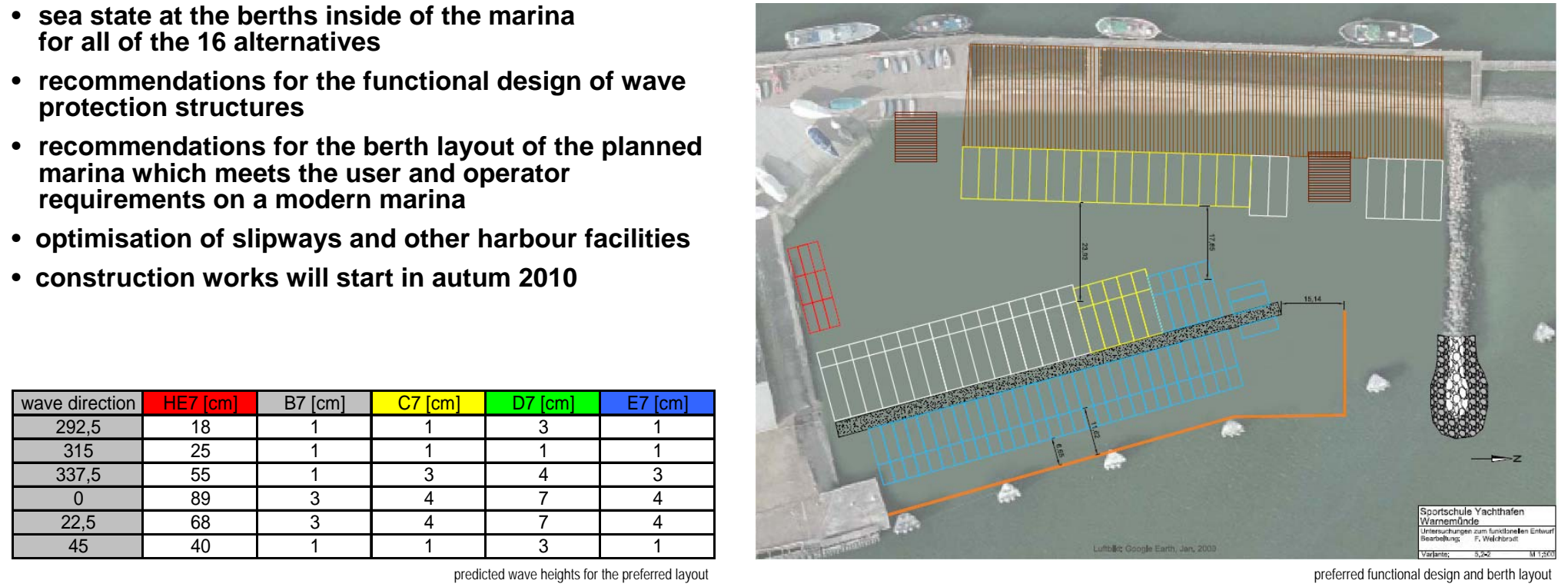